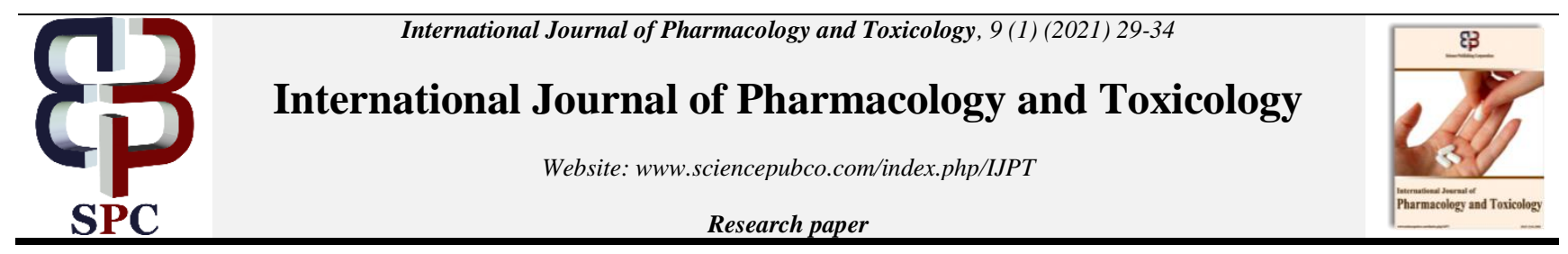

\title{
Effect of carissa edulis (VAHL) apocynaceae stem bark on hematological parameters in ccl $\neg 4$ induced albino rats
}

\author{
Y.Y. Izam ${ }^{1 *}$, B.B. Bukar ${ }^{1}$ \\ ${ }^{1}$ Department of Pharmacology, Faculty of Pharmaceutical Sciences, University of Jos \\ *Corresponding author E-mail: izamyo@unijos.edu.ng
}

\begin{abstract}
Aim/Objectives: There are claims that Carissa edulis has positive effects on hematological parameters. The present study was conducted to evaluate the safety and claimed hematological effect of Carissa edulis on rats intoxicated with carbon tetrachloride.

Method: Thirty six male albino rats were randomly allotted to six groups of six rats per group. The animals were treated with (250, 500 and $1000 \mathrm{mg} / \mathrm{kg}$ of the stem bark extract of Carissa edulis. The extract was administered daily by gavage to the animals for 28 consecutive days. The $50 \% \mathrm{v} / \mathrm{v}$ Carbon tetrachloride $\left(\mathrm{CCl}_{4}\right)$ and olive oil was gavaged twice a week. The animals of the normal control group were given $5 \mathrm{ml} / \mathrm{kg}$ of distilled water while those of the $\mathrm{CCl}_{4}$ group were administered $\mathrm{CCl}_{4}$ only twice a week.

Result: Results of the study showed that the $\mathrm{CCl}_{4}$ group caused a significant decrease in most of the hematological parameters while the extract treated groups showed a significant increase in these parameters.

Discussion / Conclusion: This suggests that the ethanolic stem bark extract has erythropoietic, thrombopoietic and positive effect on the immune system.
\end{abstract}

Keywords: Carissa edulis; Thrombopoietin; Erythropoietin; Hematological Parameters; CCl $_{4}$ and Gavage.

\section{Introduction}

\subsection{Herbal medicine}

The utilization of herbal medicines by practitioners for treatment of diseases remains the basis of healthcare system and is gaining increasing popularity particularly among the rural populace in the developing countries. Its rising popularity could be ascribed to its advantage of being efficacious and also a cheap source of medical care. There is a growing disillusion with modern medicine coupled with the misunderstanding that herbal products being natural may be without adverse and toxic effects associated with conventional medicines (Ogbonnia et al., 2010).

\subsection{Hematological investigations and health status}

Various workers have shown that hematological investigation could be employed to assess the physiological status of an animal (Kakade et al., 1974, Degruchy 1976) and an assessment of hematological parameters can be employed to determine the extent of harmful effect of foreign compound including plant extract on blood. Also cells naturally contains enzymes for their functions and damages to cellular membrane could lead to the run off of the enzymes into the blood where their occurrence or activities can simply be considered as an index of cellular integrity (Coles 1989, Coppa et al., 2002). Further, certain plasma biochemistry might be used to identify tissue injury (Patti \& Kulkarni 1993).

\subsection{Hepatotoxicity}

Drug induced liver toxicity is a major rationale for hepatic dysfunction (Abound 2007). Oxidative stress is measured as a mechanism contributing to the commencement and development of hepatic damage in a variety of liver disorders. Cell damage takes place when there is a surplus of reactive species resulting from oxygen and nitrogen on deficiency of antioxidants (Girish \& Pradhan 2008).

Oxidative stress involving enhanced production of reactive oxygen species (ROS) has been implicated in the etiology of many human diseases. Antioxidants capable of neutralizing ROS and their actions are known to be beneficial. In this context, natural dietary components with antioxidants actions can be significant (Bandyopadhyay et al., 1999, Yamamoto 2000).

\subsection{Background and justification of the study}


Hematology refers to the study of the number and morphology of the cellular components of blood basically the red blood cells (erythrocytes), white blood cells (leucocytes) and the platelets (thrombocytes) in addition to the application of the outcome in the diagnosis and monitoring of disease (Merck 2012).

Hematological studies are of ecological and physiological importance in helping to understand the connection of blood characteristics to the environment (Ovuru \& Ekweozor 2004).

Hematological complications consist primarily of irregularities in the functions morphology and metabolism of erythrocytes, leucocytes and platelets (Comazzi et al., 2004). Blood disorders that have an effect on the RBC consist of anemia which is characterized by low number of RBC and symptoms include; fatigue, pale skin and shortness of breathe with exertion. Cases of anemia include; Iron deficiency anemia, anemia of chronic diseases, pernicious anemia, $\mathrm{B}_{12}$ deficiency aplastic anemia, autoimmune hemolytic anemia, thalassemia, sickle cell anemia and polycythemia (Richard et al., 2008).

A range of disorders can cause diseases in white blood cells. This type of white blood cells decrease is normally the neutrophils, in this instance the decrease may be called Neutropenia or granulocytopenia (Lee et al., 2006). Lymphocytopenia is defined as total lymphocyte count below $10 \times 10^{4} \mathrm{~g} / \mathrm{l}$, the cells most frequently affected are the $\mathrm{CD}^{+} \mathrm{T}$ cells (Heinz 2008).

Most platelets disorders are as a result of an inadequate number of platelets, a condition identified as thrombocytopenia (Heinz 2008).The categorization of these disorders can be divided into two; congenital and acquired disorder (Heinz 2008).

Most conventional ways of managing anemia, neutropenia and thrombocytopenia may be expensive, have undesirable side effect, hurting to the patient or are not readily accessible. Blood transfusion restricts its usefulness because of the risk of infection, formation of antibodies which could make a late transplant difficult or cause hemoglobin fluctuation (Saunders et al., 2007).

Iron supplements regularly used in anemic disorders often lead to diarrhea, epigastric abdominal discomfort and in some instances increase in infectious diseases and morbidity in areas where bacterial infection are widespread(Tobilli \& Brignoli 2007).

Epogen used to treat anemia resulting from Chronic kidney disease can lead to high blood pressure, crippling cluster migraine, joint pains and clotting at the infection sites, skin rash, flu-like symptoms, allergic reactions, seizures, thrombotic events along with other possible side effects (Drueke et al., 2006).

In view of all these setbacks, there is therefore need to develop agents that are effective, cheaply available with minimal side effect as the alternative medical intervention. Unlike conventional drugs which are based on a single active ingredient aiming just one hematological component, the plant derived agents encompasses a cocktail of chemical components that act together to bring back a normal physiological state. Necessitating an urgent need to develop agents that are effective, cheaply available with minimal side effect as alternative means of treatment.

Like other terrestrial plants, Carissa edulis has ethno pharmacological significance and has also been exploited by the local people in search of remedies for different ailments to increase strength and manage hematological disorders (Tolo et al., 2006). Its effect in these activities has not been scientifically studied or validated. It was against this background that this study was undertaken to scientifically test the hematological claimed effect of the plant extract in rats.

Carissa edulis (CE) belong to the family Apocynaceae; it was formerly identified as C. pubescence (Irvine 1961, Hutchinson \& Dalziel 1963). The plant is regularly known among Hausa people in Northern Nigeria as "Cizaki" and in Somalia as Adishawel. The English name of the plant is Arabic numnum. Other common names include: endelkoring-noeminaem (Africana) 'agam' (Tigrigna and Amharic), 'emir' (Arabic), Muyonzo (Luganda), and 'mianoo-mboo, (Swahili) and Impambalamyoloko, (Sofowara 1986).

Carissa edulis is a spiny, much branched small tree shrub, up to $105 \mathrm{~m}$ in height, with a milky sap, bark grey, smooth young branchlets with or devoid of hairs, pine simple, straight, $2-5 \mathrm{~cm}$ long. Leaves ovate to ovate-elliptic lateral in veins, obscure, apex tapering, often with a bristle like tip, base rounded to shallowly. Flowers white tinged with purple, red or pink. Fruits ovoid to just about spherical. The fruits are red black ripening to purplish black.

Carissa edulis is broadly used for the treatment of a variety of ailment but little or no interest has been shown on its hematological benefits. Hence the need to investigate the effect of Carissa edulis stem bark on some hematological parameters on carbon tetrachloride induced Wistar albino rats.

\section{Materials and methods}

\subsection{Collection and identification of plant extract}

The stem bark of Carissa edulis were collected from Fursum East, Jos East Local government of Plateau state on the $30^{\text {th }}$ of January 2016. The plant was identified and authenticated by Mr. J.J Azila of the Federal College of Forestry Jos. A voucher specimen number UJ/PCG/HSP/95A09 was issued and the specimen put in the faculty herbarium for reference. The stem bark were removed from the stems and air dried at room temperature for fourteen (14) days, the dried parts were powered using mortar and pestle and sieved with 29 mesh size. The powdered part was extracted with $700 \mathrm{ml} 70 \% \mathrm{v} / \mathrm{v}$ aqueous ethanol by means of the soxhlet extraction method for 72 hours. The resultant filtrate was evaporated to dryness on steam bath at $40^{\circ} \mathrm{C}$ to provide a brownish extract that was stored in air tightcontainers and preserved in refrigerator.

\subsection{Animals}

Wistar albino rats weighing between (150-220) grams obtained from experiment animal house of the department of Pharmacology University of Jos were used for the study. The rats were fed with standard animal pellets (Pfizer Feeds Nigeria), given water ad libitum and maintained in a well-ventilated room.

\subsection{Preliminary phytochemical studies of Carissa edulis extract}

Phytochemical assessment of the ethanolic stem bark extract of Carissa edulis was carried out to identify the presence or absence of secondary metabolites. (Alkaloids, Anthraquinone, cardiac glycosides, carbohydrate, Flavonoids, saponins, Tannins and steroids) by means of standard methods. 


\subsubsection{Test for alkaloids}

The extract $(0.5 \mathrm{~g})$ was tainted with $5 \mathrm{ml}$ of $1 \%$ aqueous hydrochloric acid on a steam bath, the resultant mixture was filtered and treated with a small amount of Mayer's reagent and the final $1 \mathrm{ml}$ of the filtrate was treated with picric acid solution, precipitation with either of the reagents was taken as a preliminary indication for the presence of alkaloids in the extract (Trease \& Evans 1989).

\subsubsection{Test for anthraquinones}

Borntrager's test was used to find out the presence of anthraquinones. Half gram of the extract was measured into the test tube $5 \mathrm{ml}$ chloroform was added into the test tube and shaken for 5 minutes and the final filtrate was shaken with the same volume of $100 \%$ ammonia solution. A pink violet or red color in the ammonia (lower layer) signifies the presence of free hydroxyl anthraquinones (Trease \& Evans 1989).

\subsubsection{Test for cardiac glycosides}

Salkowski test was employed in which $0.5 \mathrm{~g}$ of the extract was weighed and dissolved in $2 \mathrm{ml}$ of chloroform. Sulphuric acid was carefully added to form a lower layer. A reddish brown color at the interface indicates the presence of a steroidal ring of a glycone portion of cardiac glycosides (Sofowara 1993)

\subsubsection{Test for carbohydrates}

Few drops of Molisch's reagents were added to $2 \mathrm{ml}$ of the dissolved Carissa edulis extract, concentrated sulphuric acid was allowed to run down the tending tube slowly. The interface was observed for a purple color, which is a typical of carbohydrates (Trease \& Evans 1989).

\subsubsection{Test for flavonoids}

Carissa edulis extracts $(0.5 \mathrm{~g})$ was dissolved in $2 \mathrm{ml}$ of dilute sodium hydroxide solution. A few drops of concentrated sulphuric acid were added to it and the presence of flavonoids was pointed out if the solution becomes colorless (Trease\& Evans 1989).

\subsubsection{Test for tannins}

0.5 gram of Carissa edulis extract was dissolved in $1 \mathrm{ml}$ of distilled water, stirred and filtered. $5 \%$ of ferric chloride was added to the filtrate a blue-black or green precipitation was indicative of the presence of tannins (Trease\& Evans 1989).

\subsubsection{Test for saponins}

0.5 gram of Carissa edulis extract was dissolved in $5 \mathrm{ml}$ of water in a test tube. The resultant mixture was shaken well and warmed for one minute, frothing which persist on warming was taken as a preliminary indication for the presence of saponins (Trease\& Evans 1989).

\subsubsection{Test for steroids and terpenes}

Carissa edulis (2.0g) was dissolved in $15 \mathrm{ml}$ of $95 \%$ alcohol and boiled in steam bath the resulting filtrate was evaporated to dryness. The residue was then dissolved in $10 \%$ of anhydrous chloroform and filtered. The resulting filtrate was mixed with $1 \mathrm{ml}$ acetic anhydride followed by the adding of $1 \mathrm{ml}$ of concentrated sulphuric acid to run-down the wall of the test tube once the test tube was inclined and a layer beneath was formed. The test tube was observed for green and reddish coloration which is an indication of the presence of steroids and terpenes (Trease\& Evans 1989).

\subsection{Determination of ld50 of Carissa edulis}

Acute toxicity study was carried out for the stem bark extract using the method of Lorke 1983.This was done in two phases. In the first phase, nine (9) rats were randomly alienated into 3 groups of three (3) rats per group and were given 10,100 and $1000 \mathrm{mg} / \mathrm{kg}$ of the extract of Carissa edulis orally (via a cannula) respectively. The rats were observed for signs of adverse effects and death for 24 hours. Based on the result of the phase one study, the procedure was repeated using another set of three rats randomly alienated into 3 (three) groups of one rat each, given 1600, 2900 and $5000 \mathrm{mg} / \mathrm{kg}$ bodyweight of the extracts respectively for 24 hours. The rats were observed for signs of toxicity which comprise of but not limited to paw ticking, salivation, stretching, rubbing of nose on the floor and walls of the cage, change in body weight and death.

\subsection{Hematological studies}

Thirty-six (36) albino rats weighing between $(150-220 \mathrm{~g})$ were randomly divided into six groups comprising of six rats each. Normal control, standard drug, carbon tetrachloride treated group and the three test groups for the stem bark extracts. The standard drug used was silymarin. To study the hematological effect against carbon tetrachloride induced albino rats. Carissa edulis stem bark (250, 500 and $1000 \mathrm{mg} / \mathrm{kg}$ body weight) were given daily by gavage to the animals for 28 consecutive days. The $50 \% \mathrm{v} / \mathrm{v} \mathrm{CCl}$ in olive oil was gavaged through gastric tube twice a week on the third and seventh day of each week and with vehicle on the rest of the days while the animals of the silymarin standard group were treated with standard drug silymarin in water at a dose of $50 \mathrm{mg} / \mathrm{kg}$ daily for 28 consecutive days alongside $\mathrm{CCl}_{4}$ on the third and seventh day of each week.

On the $29^{\text {th }}$ day each rat was anaesthetized with ethyl ether, the animals were then sacrificed and blood sample collected via the jugular vein into heparinized capillary tubes for hematological evaluations.

Hematological Evaluations

Blood samples collected via the jugular veins into heparinized capillary tubes were used to evaluate the hematological parameters, these include, the red blood cells count, white blood cell count, platelet count, packed cell volume, neutrophils, lymphocyte, monocyte, eosinophil, basophil and hemoglobin concentration. 


\subsection{Statistical analysis}

The results were expressed as mean SEM where applicable. The data used were subjected to ANOVA (Analysis of Variance) using SPSS software (version-20) and each stage ANOVA was significant a Post-Hoc test (Fishers Least Significant Difference) was carried out. The difference was taken to be statistically significant at $\mathrm{p}<0.05$

\section{Results}

\section{Phytochemical Screening of the Ethanolic Stem-Bark Extract of Carissa edulis}

The preliminary phytochemical test for the stem bark extracts was positive for saponins, tannins, flavonoids, carbohydrate cardiac glycosides and steroids. Tannins, flavonoids, carbohydrates and steroids were highly present while alkaloids and anthraquinones were absent.

\section{Determination of LD50 of the Stem Bark Extract of Carissa edulis in Rats}

Even at a dose of $5000 \mathrm{mg} / \mathrm{kg}$ there was no record of death, the animal was calm, non-aggressive, decreased exploratory activities and non-stereotype behaviors.

Table 1:Effect of the Ethanolic Stem Bark Extract of Carissa Edulis on Hematological Parameters of Ccl ${ }_{4}$ Treated Rats

\begin{tabular}{|c|c|c|c|c|c|c|c|c|c|c|}
\hline Treatment & WBC & RBC & PLATELETS & PCV & NEU & LYM & MONO & EOSIN & BASO & HB \\
\hline A & $5.43 \pm 0.15$ & $4.83 \pm 0.45$ & $148.00 \pm 36$ & $32.00 \pm 3.46$ & $17.66 \pm 3.06$ & $75.66 \pm 2.13$ & $6.00 \pm 2.54$ & $0.33 \pm 0.21$ & $0.50 \pm 0.22$ & $18.78 \pm 9.26$ \\
\hline B & $5.65 \pm 0.68$ & $6.10 \pm 0.45^{\mathrm{a}}$ & $118.50 \pm 6.03$ & $39.00 \pm 2.95^{\mathrm{a}}$ & $18.50 \pm 1.87$ & $76.50 \pm 4.66$ & $3.00 \pm 1.34$ & $1.00 \pm 0.44$ & $0.83 \pm 0.16$ & $11.60 \pm 0.84$ \\
\hline $\mathrm{C}$ & $9.70 \pm 55^{\mathrm{ab}}$ & $3.35 \pm 0.20^{\mathrm{ab}}$ & $144.66 \pm 8.5$ & $23.00 \pm 93 \mathrm{a}^{\mathrm{b}}$ & $50.00 \pm 4.08^{\mathrm{ab}}$ & $46.50 \pm 4.67$ & $2.00 \pm 0.44^{\mathrm{a}}$ & $1.50 \pm 0.22$ & $0.16 \pm 0.1$ & $6.67 \pm 0.73$ \\
\hline E & $8.26 \pm 1.72^{\mathrm{ab}}$ & $7.30 \pm 0.38^{\mathrm{abc}}$ & $261.33 \pm 34.95^{\mathrm{abc}}$ & $48.33 \pm 2.95^{\mathrm{abc}}$ & $24.33 \pm 2.01^{\mathrm{ac}}$ & $71.00 \pm 2.84^{c}$ & $3.33 \pm 1.42^{\mathrm{c}}$ & $1.33 \pm 021$ & $-a b c$ & $13.33 \pm 0.53$ \\
\hline G & $7.88 \pm 1.61$ & $6.60 \pm 0.07^{\mathrm{ac}}$ & $162.33 \pm 10.99$ & $43.66 \pm 0.76^{\mathrm{abc}}$ & $28.00 \pm 2.06^{\mathrm{abc}}$ & $69.33 \pm 3.10^{c}$ & $0.66 \pm 0.21 \mathrm{a}$ & $1.33 \pm 0.55$ & $0.66 \pm 0.21$ & $12.13 \pm 0.34$ \\
\hline I & $8.55 \pm 0.14^{\mathrm{ab}}$ & $5.45 \pm 0.13^{c}$ & $158.50 \pm 3.13$ & $37.50 \pm 2.04^{\mathrm{bc}}$ & $23.00 \pm 0.93^{\mathrm{c}}$ & $72.50 \pm 0.76^{c}$ & $0.50 \pm 0.22^{\mathrm{a}}$ & $3.00 \pm 0.89^{\mathrm{abc}}$ & $1.00 \pm 0.00 \mathrm{ac}$ & $10.20 \pm 0.06$ \\
\hline LSD & 2.61 & 0.81 & 63.71 & 6.87 & 6.46 & 8.20 & 3.07 & 1.15 & 0.44 & NS \\
\hline
\end{tabular}

KEY:

Groups $(\mathrm{A})=$ Normal Control (distilled water)

Groups $(\mathrm{B})=$ Standard Drug (silymarin)

Groups $(\mathrm{C})=\mathrm{CCl}_{4}$,

Groups $(\mathrm{E})=250 \mathrm{mg} / \mathrm{Kg}($ Bark $)+\mathrm{CCl}_{4}$,

Groups $(\mathrm{G})=500 \mathrm{mg} / \mathrm{Kg}($ Bark $)+\mathrm{CCl}_{4}$,

Groups $(\mathrm{I})=1000 \mathrm{mg} / \mathrm{Kg}($ Bark $)+\mathrm{CCl}_{4}$

LSD = Least Significant Difference

Means tagged with superscript ' $a$ ' are significantly different compared to Normal Control at $\mathrm{p}<0.05$

Means tagged with superscript ' $b$ ' are significantly different compared to Standard Drug at $p<0.05$

Means tagged with superscript ' $c$ ' are significantly different compared to $\mathrm{CCl}_{4}$ at $\mathrm{p}<0.05$

Means tagged with superscript $\mathrm{a}, \mathrm{b}$ and ' $\mathrm{c}$ ' are significantly different compared to Normal control, Standard Drug and $\mathrm{CCl}_{4}$ at $\mathrm{p}<0.05$; value are Mean \pm SEM

\section{Table 1: Effect of the Ethanolic Stem Bark Extract of Carissa edulis on Hematological Parameters of $\mathrm{CCl}_{4}$ treated $\mathrm{Rats}$}

The values of the blood indices were significantly difference between the treatment groups at $\mathrm{p}<0.05$ except for HB which had the same level between the treatment groups.

In WBC, there was a significant increase in all the groups compared to the normal control group.

For $\mathrm{RBC}$, the $\mathrm{CCl}_{4}$ group had the most significantly lower RBC count than the remaining groups. Other groups were significantly higher than the $\mathrm{CCl}_{4}$ group.

For Platelet, $250 \mathrm{mg}$ of the stem bark extract had the highest concentration of platelets compared to the $\mathrm{CCl}_{4}$ group the remaining groups (500 and $1000 \mathrm{mg} / \mathrm{kg}$ ) had the same level of platelets with the $\mathrm{CCl}_{4}$ and normal control group.

For $\mathrm{PCV}$, the least value was in the $\mathrm{CCl}_{4}$ group which was significantly lower than normal control at $(32.00 \pm 3.46)$ i.e. the extract treated groups were significantly higher than the $\mathrm{CCl}_{4}$ and normal control groups.

For Neutrophils, the highest level was observed in the $\mathrm{CCl}_{4}$ group at $(50.00 \pm 4.08)$ which was significantly higher than the other groups.

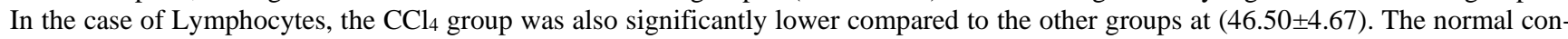
trol groups had the same level with the other groups except $\mathrm{CCl}_{4}$ group. The groups treated with the three concentrations of the stem bark extract showed significant increase in Lymphocyte level.

For monocytes, 500 and $100 \mathrm{mg}$ of the stem bark extract groups and also the Silymarin group had the same level with the CCl $\mathrm{group}_{\text {. }}$ The values for all the other groups were significantly lower than the normal control group.

In eosinophils, the highest level was observed in 1000mg bark extract group which was significantly higher compared to the other groups at $(3.00 \pm 0.89)$.The remaining groups except $1000 \mathrm{mg}$ of the stem bark had the same level with the normal control group.

For Basophils, all the treatment groups had the same level with normal control except 1000mg group of the bark extract which is significantly higher than the $\mathrm{CCl}_{4}$ and the normal control groups.

\section{Discussion}

The blood is a very important fluid found in humans and other animals. It conveys gases and nutrients to all organs and tissues of the body and carries away waste materials as well as regulation of body temperature. The blood transports foreign body which might be 
harmful to all parts of the body leading to initiation and development of diseases. The echelon of blood components is characteristics of one's health status (Ohaeri \& Eluwa 2011, Sexena et al., 2011).

The fundamental reason for assessing the RBC is to determine the level of anemia and to evaluate usual erythropoiesis (Momoh \& Damazio 2014). The result of this study showed that the $\mathrm{CCl}_{4}$ group had the least $\mathrm{RBC}$ and PCV while the extract treated groups showed significant improvement in the levels of these parameters, this is consistent with the study of (Jorum 2016), which shows that the administration of the extract of Carissa edulis significantly boost the levels of PCV, RBC and other parameters in normal rats (Jorum 2016).The decrease in the $\mathrm{CCl}_{4}$ group may be ascribed to the cytotoxic effect and the repression of erythropoiesis while the increase in the level of RBC and PCV upon administration of the extract suggests that the extract could have trigger erythropoietin release in the kidney, which is the humoral regular of RBC production (DeGruchy 1976).

The presence of phytochemical like Flavonoids, Tannins and Terpenes in the stem bark extract of Carissa edulis may be accountable for the Hematopoietic stimulating effects (Olsson \& Aher 2006). This is in line with previous studies which showed the therapeutic and prophylactic oral administration of antioxidant supplement of plant extracts drastically increase cells hematopoietic source in animals exposed to potentially fatal dose of radiation (Wambi et al., 2008). Flavonoids, tannins and terpenes have been established to protect erythrocytes from oxidative damage (Grassman 2005). Further (Ren et al., 2003) reported that Flavonoids have a range of benefits for human health owing to their antioxidants and free radical scavenging activities as well as anti-inflammatory, antiviral and anticancer features (Naaz et al., 2007).

In the case of WBC, the study showed that there was a significant increase in the level of $\mathrm{WBC}$ in all the extract treated groups and $\mathrm{CCl}_{4}$ group compared to the normal control group. The elevation of WBC may be as a result of the stimulation of the immune defense system (Kashinath 1990) resulting to enhancement in the pace of deletion from circulation. Granulocytes-macrophage colony stimulating factor, macrophage colony stimulating factor interleukins (IL-2, IL-4 and IL-5) control the proliferation, differentiation and maturation of committed stem cells responsible for the production of WBC(Ganong 2001).In the same way, literatures have shown that increased concentration of antigen in the body results in high value of WBC(Schalm et al., 1975).

A low level of monocytes in the blood can be due to whatever thing that decreases the total WBC such as chemotherapy, infection of the blood stream and bone marrow disorders (Dawkins 1963). The result from this studies suggest that there was no significant difference between the $\mathrm{CCl}_{4}$ and the extract treated groups, probably due to the presence of $\mathrm{CCl}_{4}$ that might have triggered the elevation of the monocytes.

The coagulation of blood requires that platelets be present in adequate size and functions. The lower concentration of the stem bark extract produced significant increase in platelet level compared to the $\mathrm{CCl}_{4}$ and the normal control group. The increase in the platelet level observed may be due to the stimulation outcome on thrombopoietin (Li et al., 1999). The significant elevations in platelet level suggest that the extract may contain compounds and phytochemicals that may have stimulated thrombopoietic process in rats. The presence of Tannins has been shown to bestow antihemorhagic properties in animals (Viyaya et al., 1995, Weber et al., 2003). The effect of the extract on platelets may imply that it may be beneficial in thrombocytopenia which is a disorder characterized by relative decrease in thrombocytes usually known as platelets present in the blood. (DeGruchy 1976).

The significant decrease in lymphocyte level in the $\mathrm{CCl}_{4}$ group may be due to the inhibition of the effectors cell of the immune system while the increase in the other groups may be due to the ability of the extract to stimulate the effectors cell of the immune system resulting to an increase in lymphocyte level.

In the case of neutrophils, the highest level was observed in the $\mathrm{CCl}_{4}$ group compared to the remaining groups at $(46.50+4.67)$, this may imply that the toxic agent $\mathrm{CCl}_{4}$ probably has the ability to enhance blood component of phagocytosis (Kashinath 1990).

For the Basophil, the result from this study showed a significant increase between the $\mathrm{CCl}_{4}$ and the extract treated groups at a dose of $1000 \mathrm{mg} / \mathrm{kg}$ of the stem bark extract which suggest positive effect on the immune system. (Jorum 2016). For the eosinophils, the result showed a significant elevation in the eosinophil level at a dose of $1000 \mathrm{mg} / \mathrm{kg}$ of the extract which may also propose a positive effect on the immune system (Jorum 2016).

\section{Conclusion}

The study showed that the extract treated group showed significant increase in the levels of $\mathrm{RBC}$ and PCV compared to the $\mathrm{CCl}_{4}$ group which had the least value. This suggests that the extract could stimulate erythropoietin release in the kidney.

The stem bark extract also produced significant increase in the level of platelets, WBC, lymphocyte, basophil and eosinophil which suggest a positive effect on the immune system.

However, the active compound accountable for the hematological effect has so far not been identified in this study. The mechanism of action also remained unproven. Further research is therefore required to discover the constituents of the tested plant responsible for the hematological effect.

\section{References}

[1] Abound G \& Kaplowitz N (2007). Drug Induced Liver Injury. National Library of Medicine. National Institute of Health: 30(4), 227 294.https://doi.org/10.2165/00002018-200730040-00001.

[2] Bandyopadhyay U \& Das D, Banerjee RK (1999). Reactive Oxygen Species. Oxidative Damage and Pathogenesis. Curriculum Science, 77, 658 666.

[3] Coles C (1989). Diabetes education; Theories in practice. Practical Diabetes International 6 (5) 504.https://doi.org/10.1002/pdi.1960060504.

[4] Comazzi S, Spagnolo V \& Bonfanti U (2004). Erythrocyte changes in canine diabetes mellitus: in vitro effects of hyperglycemia and ketoacidosis. Journal on comparative clinical pathology 1(2), 199-205.https://doi.org/10.1007/s00580-004-0502-x.

[5] Coppa JA, Mussart NB \&Floranelli SA (2002). Physiological variations of enzymatic activities in blood of Bullfrog, Ranacates Beinashaw12 (13), 22-27.

[6] Dawkins M (1963). The identification of epidural space. Wiley Online Library Anesthesia/Volume 18, issue 1https://doi.org/10.1111/j.13652044.1963.tb13706.x.

[7] DeGruchy GC (1976). Clinical hematology in medical Blackwell Scientific Publication, Oxford Pp 33-57.

[8] Drueke TB, Locatalli F, Clyne N, Eckardt KU \& Macdaugall IC (2006). Normalization of hemoglobin level in patients with Chronic Kidney disease and Anemia. New Zealand Journal of Medicine 3(55), 2071-2084.https://doi.org/10.1056/NEJMoa062276.

[9] Ganong WF (2001). Review of medical physiology, Lange medical books McGraw-Hill companies' incorporation2:500

[10] Girish C \& Pradhan SC (2008). Drug Development for liver diseases: focus on Picro-liv, ellagic acid and curcumin. Fundamental Clinical Pharmacology 22(6), 623 - 632https://doi.org/10.1111/j.1472-8206.2008.00618.x. 
[11] Grassman J (2005). Terpenoids as plant antioxidant Vitamhorm 72, 505 - 535https://doi.org/10.1016/S0083-6729(05)72015-X.

[12] Heinz J (2008). Coagulation disorders Concise Manuals on Hematology and Oncology371-386.

[13] Hutchinson J \&Dalziel (1963). JM.Flora of West Africa, Vol II Crown agents for oversea government and administration, Mill-banks, London. 51 $-54$.

[14] Irvine FR (1961). Woody plants of Ghana. Oxford. University Press London Pp 616 - 18

[15] JorumOH, Piero NM \& Machocho AK (2016). Hematological Effect of Dichloromethane methanolic leaf extract of Carissa edulis (Forssk) Vahl in normal rat's models. Journal of Hematology and Thromboembolic Diseases 4:232:doi10.4172/2329-8790.10000232.

[16] Kakade ML, Rackis JJ, McGhee \& Puski GA (1974). Determination of trypsin inhibitor activity of Soy products;- a collaborative analysis of an improved procedure. Cereal Chemistry 5(1), 376-382.

[17] Kashinath RT (1990). Hypolypidemic effects of disulphide in rats with high lipids diet and/or ethanol PhD Theses University of Bangalore; Pp 221 $-25$

[18] Lee CY, Wilkinson BD, Siergrist SE, Wharton RP \& Doe CQ (2006). Brat is Miranda cargo protein that inhibits neuroblast self renewal. Dev. Cell 10(4), 441-449.https://doi.org/10.1016/j.devcel.2006.01.017.

[19] Li J, Xia Y \& Kuter DJ (1999). Interactions of thrombopoietin with the platelet complement receptor in plasma binding internalization, stability and pharmacokinetics. British Journal of Hematology106: 345https://doi.org/10.1046/j.1365-2141.1999.01571.x.

[20] Lorke D (1983).A new approach to practical acute toxicity testing. Archive of toxicology 54, 275 - 87 [Pub med].https://doi.org/10.1007/BF01234480.

[21] Merck M (2012).Hematologic reference ranges. Merck Veterinary Manual. Retrieved from http:www.merkmanual.com.

[22] Momoh, J \&Damazio OA (2014).Hepatotoxicity of Household Kerosene (HHK) on liver enzyme markers and its effects on hematological and oxidative stress parameters on Wistar albino rats. Science Journal of Medicine and Clinical Trial; 1(0), 7.

[23] Naaz F, Javed S \& Abdin MZ (2007). Hepatoprotective effect of ethanolic extract of Phyllantu samanusschumet Thorn on aflatoxin Bi-induced liver damage in Mice. Journal of Ethno pharmacology 11(3), 503 -9. https://doi.org/10.1016/j.jep.2007.07.0 17.

[24] Ogbonnia SO, Mbaka GO, Anyika EN, Ladiju O, Igbokwe HN, Emordi, JE \& Nwakakwa N (2010). Evaluation of Antidiabetics and Cardiovascular Effects of Parinaricuratellifolia Seed Extract and Anthoclistavogelli Root Extract Individually and Combined on Post Prandial and AlloxanInduced Diabetic albino Rats. British Journal of Medical Research (3), 146 - 162

[25] Ohaeri CC \&Eluwa MC (2011). Abnormal biochemical and hematological indices in trypanosomiasis as a threat to herd production US National Library of Medicine. National Institute of Health. Veterinary Parasitology 177 (3 - 4), 199 - 2002 https://doi.org/10.1016/j.vetpar.2011.02.002

[26] Olsson A \&Aher SM (2006). Early erythropoietin for presenting red blood cell transfusion in preterm and/or birth weight infants Cochrane database system 2006 1:3.https://doi.org/10.1002/14651858.CD004863.pub2.

[27] Ovuru SS \&Ekweozor IK (2004). Hematological changes associated with crude oil ingestion in experimental rabbits. African Journal of Biotechnology 3(1), 346-48.https://doi.org/10.5897/AJB2004.000-2064

[28] Patti M \&Kulkarni RS (1993). Ovarian and hepatic biochemical response to Sumaach (a crude form of HCG in Fish, Notopteruspallas under pesticide treatment, Gobies 2(1), 255-259.

[29] Ren W, QiaoWang Z \& Zhan L (2003). Flavonoid promising anticancer agent medicinal research reviews 23, 519 534https://doi.org/10.1002/med.10033.

[30] Richard AM, Matthew RP, Naïf Z \&Abraham J (2008). Henry’s Clinical Diagnosis and Management by Laboratory Methods. Philadelphia, PA: Elsevier/Saunders1; 2 .

[31] Saunders A, Hofmann A, Gombotz H, Theusinger OM \& Spahn DR (2007). Estimating the cost of blood; past present and Future directions. Best Practical Research in Clinical Anesthesiology 2(1), 271-89.https://doi.org/10.1016/j.bpa.2007.01.002.

[32] Saxena DK, Sharma SK \& Sambi SS (2011). Well comparative extraction of Cotton seed oil by n-Hexane and ethanol ARPN. Journal of Engineering and Applied Sciences, 6(1), $84-89$

[33] Schalm OW, Jain NC \& Croll EJ (1975). Veterinary hematology ( $3^{\text {rd }}$ ed) Philadelphia lea and Febigar, 498 - 512.

[34] Sofowara A (1986). The state of medicine plant research in Nigeria. $1^{\text {st }}$ Edition University Press Limited. Ife Nigeria. page 145 - 8.

[35] Sofowora A (1993).Medicinal Plant and Traditional Medicine in Africa. 2 - 47. Spectrum Books Limited Ibadan Nigeria

[36] Tobilli JE \&Brignoli R (2007). Iron (1ll)-hydroxide polymaltose complex in Iron deficiency anemia/review and meta- analysis. ArzneimitleforShung 5(7), 431-8.https://doi.org/10.1055/s-0031-1296692.

[37] Tolo FM, Rukunga GM, Muli FW, Njagi EN \& Njue W (2006). Antiviral activity of the extract of a Kenyan medicinal plant Carissa edulisagainst herpes simplex virus. Journal of Ethno pharmacology 10(4), 92-9.https://doi.org/10.1016/i.jep.2005.08.053.

[38] Trease \&, Evans WC (1989). Pharmacognosy, $13^{\text {th }}$ (Eds). ELBS/BailliereTindall, London: pp. 345 - 346, 535 - 536, 772 - 773.

[39] Viyaya K, Ananthan S \& Nalini R (1995). Antibacterial effects of the Aflavin, polyphenol 60 (CamellaSinensis). Euphorbia hirta on shingella Supp. A cell culture study. Journal of Ethno pharmacology, 45,115 -118.https://doi.org/10.1016/0378-8741(95)90039-X.

[40] Wambi C, Sanzari J, Wanxs S, Nuth M \&Davis J (2008). Dietary antioxidants protect hematopoietic cells and improve animal survival after total body irradiation. Radiation research, 169, 9: 384 -6.https://doi.org/10.1667/RR1204.1.

[41] Weber ME, Wiedicke HM, Kudrass HR, Kudrass H \& Erlenkeuser H (2003).Physical Properties of 39 Sediment Cores from the Bengal Fan and Northeast Indian OceanPANGAEA2003.

[42] Yamamoto A (2000). Reversal of Neuropathology and Motor Dysfunction in a Coordinational Model of Huntington's disease. Pub med. US National Library of Medicine National Institutes of Health 101(1), 57 - 66.https://doi.org/10.1016/S0092-8674(00)80623-6. 